\title{
Patient-reported outcomes and complication rates after lateral maxillary sinus floor elevation: a prospective study
}

\author{
Carlo Rengo ${ }^{1}$ (i) $\cdot$ Antonino Fiorino $^{2} \cdot$ Alessandro Cucchi $^{3} \cdot$ Antonio Nappo $^{1}$. \\ Emanuele Randellini ${ }^{4} \cdot$ Paolo Calamai $^{5} \cdot$ Marco Ferrari $^{1}$
}

Received: 17 October 2020 / Accepted: 21 December 2020 / Published online: 23 February 2021

(C) The Author(s) 2021

\begin{abstract}
Objectives Oral surgery morbidity is highly variable based on patients' characteristics and kind of surgical intervention. However, poor data are available in the literature regarding patient outcomes after oral surgery. The aim of this retrospective study was to evaluate patient-reported outcome and complication rates after maxillary sinus floor elevation.

Materials and methods Data from the records of patients undergoing maxillary sinus elevation have been collected from a private dental office. Patient-reported outcome has been assessed using a $100-\mathrm{mm}$ visual analog scale to evaluate the postoperative pain $\left(\mathrm{VAS}_{\text {pain }}\right)$ experienced in the first week following surgery and visual rating scales to evaluate discomfort level $\left(\mathrm{VRS}_{\text {discomfort }} 0\right.$ to 4$)$ and willingness to repeat the same surgical procedure $\left(\mathrm{VRS}_{\text {willingness }}: 0\right.$ to 3$)$. Analgesics intake, swelling onset and duration, and ecchymosis have been also recorded.

Results $\mathrm{VAS}_{\text {pain }}$ showed moderate values in the first 2 days $(<50)$ post-surgery, with a tendency to progressively decrease over the next 2 days. Average assumption of painkillers was $3.93 \pm 3.03$. Discomfort level $\left(\mathrm{VRS}_{\text {discomfort }}\right)$ after surgery was low (median: 1; IR: 1-0), while willingness to undergo the same surgical procedure was very high (77.63\% of patients). Swelling and ecchymosis were experienced by $97.36 \%$ and $51.32 \%$ of patients, respectively, with a mean duration of $4.09 \pm 1.43$ and $2.21 \pm$ 2.31 days, respectively. Membrane perforation occurred in 4 cases. Other post-operative complications were not observed.

Conclusions Maxillary sinus grafting is a safe procedure, with a low complication rate and moderate morbidity that is well tolerated by patients. Particular attention is needed in case selection, surgical planning and operator expertise.

Clinical relevance The analysis of patient-reported outcomes can be of great help in surgical planning and in providing correct and adequate treatment.
\end{abstract}

Keywords Patient-reported outcomes $\cdot$ Maxillary sinus floor augmentation $\cdot$ Pain $\cdot$ Complications

\section{Introduction}

Oral surgery morbidity is highly variable based on patients' characteristics and kind of surgical intervention. However,

Carlo Rengo

carlorengo@alice.it

1 Department of Prosthodontics and Dental Materials, University of Siena, Viale Bracci, 53100 Siena, Italy

2 Dentistry Unit, Catholic University of Sacred Heart, Rome, Italy

3 Private Practice, Bologna, Italy

4 Private Practice, Fucecchio, Italy

5 Private Practice, Florence, Italy poor data are available in the literature regarding patient outcomes after oral surgery.

Actually, it is particularly difficult to objectively assess pain, since it is affected by personal control of sensations and emotions [1]. However, dental patients are more worried about pain and fear of oral surgical interventions than costs or outcomes. Therefore, management of the patient anxiety and pain is crucial in patients undergoing oral surgical procedures [2].

Generally, conventional dental implant placement causes mild to moderate pain experience [3, 4]. Implant placement in the posterior maxilla often involves additional bone augmentation procedures, when, following tooth loss, the residual alveolar ridge is reduced due to pneumatisation of the maxillary sinus or vertical resorption of the edentulous bone crest $[5,6]$. 
Despite the introduction of xenograft or synthetic biomaterials has significantly reduced the surgical morbidity [7-10], lateral maxillary sinus floor elevation (LSFE), as first described from Boyne $\mathrm{J}$ and James RA [11], is still considered an invasive technique among bone regeneration procedures of the posterior maxilla [12]. Therefore other types of procedures have been suggested, including trans-crestal sinus floor elevation [13], graft-less sinus augmentation technique [14], short implants [15], tilted implants [16], pterygoid [17], or zygomatic implants [18].

Short implants are definitely associated with a minor discomfort for the patient compared to all bone augmentation procedures [19] and survival rate of implantsupported prosthesis with implant/crown ratio up to 3 is still very high [20]; thus, this approach represents a valid and predictable alternative. While some studies have shown that the success rates of short implants are even higher than those of long implants in augmented bone [21], other groups reported that the success rate is comparable with standard implants, showing less biological complications but more prosthetic complications [22].

However, recent reviews provided contradictory findings pointing out that short implants fail at an earlier stage compared to standard implants [21, 23].

Probably, these higher failure rates could be related to loading protocols or lack of adequate primary stability that could be lower for short implants [24].

Obviously, when the residual bone height is inadequate even for extra-short implants, it is necessary to resort to bone regeneration techniques [22].

Trans-crestal approach is the main alternative to LSFE and it is generally preferred by patients due to reduced morbidity, comparable to implants inserted in native bone [7], thus lower than with the lateral approach, and to the shorter period of rehabilitation [25].

The LSFE is however a predictable technique [26]. Moreover, the use of new tools such as piezoelectric devices [27] and less invasive clinical protocols [28] flap designs [29] may represent a great advantage in terms of patient benefit, pain experience, and clinical outcome. To date, there is a lot of data on the success and complication rates of this technique; however, the literature does not report the patient's experience after this surgery [30].

Therefore, the aim of this study was to evaluate various patient-reported outcome measures (PROMs) and early complication rates in patients treated with LSFE. The primary outcome was to evaluate, through a VAS scale, the level of pain experienced by patients in the 7 days following surgery. Secondary outcomes were the evaluation of surgical discomfort, the willingness to undergo surgery again, the amount of painkillers taken, the onset and duration of swelling, and ecchymosis.

\section{Methods}

\section{Study design and patient selection}

The study was designed as single-center, non-randomized, prospective, observational study. All consecutive patients referred to the author for mono-lateral LSFE were enrolled and treated between February 2019 and January 2020.

Treatment planning was discussed and benefit/risk ratio was explicated to each patient that subsequently signed a written informed consent form for participation in the present study, for processing of personal data and images, and for publishing purposes, approved by local ethical committee ("Azienda Ospedaliera - Universitaria Senese" Ospedale "Le Scotte" Siena, Italy). The study obtained approval by the board of the Department of Prosthodontics and Dental Materials, University of Siena, Italy, in accordance with the Helsinki Declaration for biomedical research involving human subjects and Good Clinical Practice Guidelines (General Assembly of the World Medical Association 2014). Registration on www.clinicaltrials.gov was not necessary due to the study design, which was conducted following the STROBE guidelines [31].

The inclusion criteria were as follows: edentulism in posterior maxilla that required implant-supported rehabilitation, alveolar atrophies classes $\mathrm{A}$ or $\mathrm{C}$, according to Chiapasco et al. [32], with residual bone height $(\mathrm{RBH})<6 \mathrm{~mm}$, bone width $\geq$ $5 \mathrm{~mm}$, and no vertical resorption. Exclusion criteria were: age $<18$ years, any systemic disease contraindicative of surgery, un-treated periodontal disease, uncontrolled diabetes, poor horal hygiene, endodontic lesions at adjacent teeth, history of sinusitis (including present maxillary sinus infection or pathology). Smokers were informed about the increased risk of surgery and were advised to reduce/stop smoking.

\section{Pre-surgical procedure}

After the collection of accurate medical history, a clinical and radiological evaluation (OPT and peri-apical $\mathrm{x}$-rays) of each patient was performed to set the correct therapeutic plan for implant-prosthetic rehabilitation. Subsequently, patients underwent cone beam computed tomography (CBCT) x-ray examination extended to the osteo-meatal complex to evaluate bone volumes, patency of the ostium, and the presence of alterations or infections of the endosinusal mucosa. Nonsurgical or surgical treatments of sinusal disease were mandatory prior to the following interventions.

Patients with periodontitis underwent cause-related periodontal therapy and were adherent to maintenance care for at least 6 months before the beginning of the study.

All patients underwent professional oral hygiene 1 week before the surgery. 
Prophylactic oral premedication was adopted using amoxicillin clavulanate $(1 \mathrm{~g} / 8 \mathrm{~h})$ or clindamycin $(600 \mathrm{mg} / 12 \mathrm{~h})$ in patients allergic to penicillin, starting 1 day before surgery and for 7 days after surgery. All patients rinsed their mouth for 2 min with a $0.2 \%$ chlorhexidine solution prior to surgery.

\section{Surgical procedure}

All sinus lifts were performed by a single experienced operator under local anesthesia with articaine chloridrathe $4 \%$ and adrenaline 1:100.000, through infiltration in the buccal vestibule, at the infraorbital foramen and major palatine foramen. A full-thickness flap was elevated to expose the alveolar crest and the lateral wall of the maxillary sinus, performing a midcrestal incision and a vertical mesial releasing incision, mesial to the last tooth before the edentulous site. The flap was raised apically to the extent to allow the positioning of a periosteal elevator or retractor, to protect soft tissues, at about $5 \mathrm{~mm}$ from the apical edge of the osteotomy. The triangular flap design was respected for all patients. Using a round bur mounted on a contra-angle and under sterile saline irrigation, a superficial osteotomy was performed on the lateral sinus wall until leaving a thin layer of bone subsequently removed with a round diamond tip mounted on a sonic device (Sonosurgery, TKD, Italy) under sterile saline irrigation. The coronal margin of the osteotomy was approximately $3 \mathrm{~mm}$ from the sinus floor.

A flat oval "elephant foot" shaped tip mounted on the sonic device was used to gently elevate the sinus membrane from the osteotomy borders. Schneider membrane elevation was continued with hand instruments until detaching the medial sinus wall, elevating the sinus floor membrane distally and mesially to allow for graft placement in the future implant receptor site, and paying particularly attention in the presence of intercalated edentulism at the level of the roots protruding in the maxillary sinus. During the surgical procedure, the possible presence of membrane perforations was evaluated through direct observation using $\times 2.5$ magnification loupes. In case of membrane perforation, repair was attempted placing a resorbable collagen membrane (Bio-Gide®; Geistlich Pharma, AG, Switzerland).

Sinus was then filled with a bovine bone graft (Bio-Oss ${ }^{\circledR}$ Large granules $1 \mathrm{~mm}-2 \mathrm{~mm}$; Geistlich Pharma, AG, Switzerland) previously mixed with sterile saline solution. The graft was initially packed tightly against the medial wall, then against the anterior and posterior compartments, and finally over the lateral sinus wall. A resorbable collagen mem-

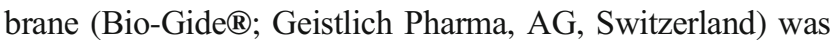
applied to cover the osteotomy and the flap was repositioned, without need of passivation or periosteal releasing incisions, and sutured with non-resorbable sutures (4.0 Polyester; Omnia, Italy).

\section{Post-surgical procedure}

Antibiotic prophylactic was continued for 7 days after surgery and analgesics were prescribed (ibuprofen $600 \mathrm{mg}$ : 1 tablet immediately after surgery and 1 tablet after $8 \mathrm{~h}$ ). Analgesics prescription for the days following the surgery was ibuprofen $600 \mathrm{mg} /$ ad libitum. Patients applied ice packs to their face for $15 \mathrm{~min}$ on and $15 \mathrm{~min}$ off for $2 \mathrm{~h}$, and were asked to rinse at least twice a day with a $0.12 \%$ chlorhexidine solution and to follow a cold and soft/liquid diet for 14 days. Patients were also asked to avoid blowing their noses and a nasal decongestant spray (Tonimer Lab Hypertonic, Ist. Ganassini, Italy) was prescribed for 10 days to help maxillary sinus drainage. Sutures were removed 2 weeks after surgery during the 14day visit.

\section{Radiographic evaluation}

An OPT x-rays exam was performed immediately after surgery and a CBCT $\mathrm{x}$-rays exam was performed 6 months after to evaluate the volume of the grafts and to plan implant placement.

Patient reported outcome measures and complications measure After surgery, the patients were given a notebook to fill in to collect the outcomes. All patients were instructed by a second investigator to complete the questionnaire, clarifying any doubts regarding interpretation. An open comment section has also been included.

Patient-reported outcomes were assessed using a 10-mm visual analogue scale (VAS) to evaluate the post-operative pain experienced in the first week following surgery and visual rating scales (VRS) to evaluate discomfort level during surgery $(0=$ none, $1=$ mild, $2=$ moderate, $3=$ intense, $4=$ very intense) and willingness to undergo the same surgery $(0=$ no problem repeating the surgery, $1=\mathrm{I}$ would do it again but I would prefer to delay, $2=\mathrm{I}$ would do it again but I expect to suffer a lot, 3 = I would never do this again). These two VRS were recorded immediately after surgery.

Analgesics intake was recorded from the 2nd to the 7th post-surgical day. Onset and duration of swelling and ecchymosis (bruising, hematoma) were also evaluated for 7 days.

Finally, all complications, either observed by the operators or by the patient, were recorded and divided into: surgical complications (venous or arterial bleeding, sinusal membrane perforation, or buccal flap laceration) and healing complications (wound dehiscence, infection/fistula, or sinusitis).

Follow-up visits were scheduled 7 days after surgery, 14 days after surgery, and then monthly up to 6 months.

For data analysis, the patients were divided into different groups according to: sex, smoking habits, hypertension, residual bone height, periodontitis, and bone class. 
Statistical methodology An Excel data collection form and data management system was used (Microsoft Excel 2011; Windows, ver. 14.0.0; Microsoft Corp., Redmond, WA, USA). All data were entered by a single blinded operator. Prior to entry, all data were evaluated in terms of accuracy and completeness. For each continuous variable the mean, median, standard deviation (SD), interquartile range (IQR), and the maximum and minimum value were reported. Hypothesis of normality was tested with the skewness/ kurtosis tests (normal distribution if $p$ value $>0.05$ ). For qualitative data frequencies, proportions and $95 \%$ confidence intervals for proportions were calculated. In bivariate analysis, proportions were compared using 2 tests. The chi-square statistic (i.e., $\chi 2$-statistic) were performed when no more than $20 \%$ of the cells of the contingency tables had frequencies of 5 or less and that no cells have expected frequencies less than 1 (Cochran, 1954). If any of the observed values was less than 5 , then a Fisher's exact test was performed. The comparison of means to evaluate statistically significant differences was performed by $t$ test, Wilcoxon rank sum test and Wilcoxon matched-pairs signed-ranks test where necessary. Between variables where it was possible to use parametric tests, the median was not reported because both respected the assumption of normality. Where a non-parametric test was used, the median is always reported. The possible linear correlation between the different variables was investigated by applying the Pearson's, or when the variables did not have a normal distribution or a nonlinear relationship, Spearman's correlation test. Correlations were reported specifying the $p$ value and the Pearson ( $r$ ) or Spearman (rs) correlation coefficient. The threshold value decided for determining the statistical significance corresponds to a $p$ value of 0.05 (5\%). Post hoc statistical power was obtained comparing the cumulative mean of VAS pain over the 7 days of observation with a known value published in the previous literature. Calculation was performed as follows: power $=\Phi\left(-\mathrm{z} 1-\alpha / 2+|\mu 0-\mu 1| \times n^{-} \sqrt{ } /\right.$ $\sigma)$. The statistician was blinded and external to working group. Data analysis was performed with STATA/IC software (StataCorp LLC, College Station, TX, USA).

\section{Results}

In total, 76 patients were treated according to the protocol procedure.

The median dose (number of vials) of anesthetic was 3 (IR, 2-4).

Osteotomy median dimensions were $10 \mathrm{~mm}$ (IQR, 8-12) of width and $7 \mathrm{~mm}$ (IQR, 6-9) of height. The surgeries had a median duration of 76 min.

All patients included for the final data analyses completed the questionnaire without omitting information. No drop-outs were reported. The characteristics and anamnestic data of overall population were collected and shown in Table 1.

\section{Patient-reported outcomes}

Pain levels assessed during the week following the surgery, as total population and sorted by different groups, are reported in Table 2. The distribution of severe pain and non-severe pain is shown in Fig. 1.

Pain level showed moderate values in the first (median, 5; IQR, 2.5; range, 0-10) and second day (median, 5; IQR, 3; range, $0-10$ ) with a tendency to decrease over the third (median, 3; IQR, 4; range: 0-8), and fourth day (median, 1; IQR, 3 ; range, $0-8$ ), showing median values of 0 from the fifth day. Total VAS average over 7 days was $2.39 \pm 1.56$. By comparing this value with those stated in the study of Merli et al. [33], it was possible to calculate a post hoc power equal to $100 \%$ with alpha error of $0.05 \%$.

Average analgesics intake during the week following the surgery was $3.93 \pm 3.03$ (median, 3; IQR, 2; range, 0-14). Relative percentages of patients assuming at least one analgesic per day are showed in Fig. 2. Among the patient-related factors analyzed, painkillers assumption was significantly higher only for smokers (mean, $5.11 \pm 3.56$ ) than nonsmokers (mean, $3.57 \pm 2.85 ; p=0.04$ ) (Table 3). A strong correlation was found between VAS values and painkillers during the first 5 days (days 1-4: $p=0.00001$; day 5: $p=$ 0.0021) (Fig. 3).

Discomfort level was low (median, 1; IQR, 1; mean, $0.79 \pm 1.01$; range, $0-4$ ) (Table 4). Patients who experienced the highest discomfort level during surgery ( 4 on a $0-4$ scale) reported statistically significantly higher VAS values for the first 3 days (mean, $96.67 \pm 5.77$; median, 100), and on the 7 th day together with patients who referred a discomfort level of 3 (day 1: $p=0.0473$; day 2: $p=0.0481$; day $3: p=0.0259$; day 7: $p=0.0401)($ Table 5).

Willingness to undergo the same surgery was very high (77.63\% of patients; median, 0 ; range, $0-3$; IQR, 0; mean, $0.34 \pm 0.75$ ) (Table 6). Patients with lowest willingness (3 on a 0 to 3 scale) reported mean VAS values statistically significantly higher on days $1(p=0.0450), 4(p=0.0241)$, and $5(p=0.0104)$ (Table 5).

Swelling was experienced by $97.36 \%$ of patients with an onset observed mostly $(59.21 \%)$ on the second day and never beyond the third day. Mean duration was of $4.09 \pm 1.43$ days. Those who had persistent swelling beyond day 5 also had significantly more pain on the 6th day $(p=0.0270)$ than the others patients. Ecchymosis was experienced by $51.32 \%$ of patients with a mean duration of $2.21 \pm 2.31$ days with an onset observed mostly (44.74\%) within the third day (Fig. 4).

Patients who developed ecchymosis in the first 2 days $(67.56 \%)$ had statistically significantly less pain on days 6 and $7(p<0.05)$. 
Table 1 Patient data and characteristics $(n=76)$

\begin{tabular}{ll}
\hline SEX (M/F) & $38 / 38$ \\
Age (y) (range) & $52 \pm 10(31-73)$ \\
Smoke & $18(23.7 \%)$ \\
Periodontal disease & $30(39.5 \%)$ \\
Systemic disease (total) & $31(40.8 \%)$ \\
Hypertension & $12(15.8 \%)$ \\
Depression & $6(7,9 \%)$ \\
Diabetes & $2(2.6 \%)$ \\
Liver disease & $2(2.6 \%)$ \\
Osteoporosis & $2(2.6 \%)$ \\
Anemia & $2(2.6 \%)$ \\
Concomitant medications & Anticoagulants $(3) ;$ antihypertensive $(2) ;$ metformina $(1) ;$ \\
& antidepressive $(3) ;$ eutirox $(3) ;$ FANS $(1) ;$ \\
Alterations of the sinusal mucosa & $8(10.5 \%)$ \\
& $7=$ mild thickening of the mucosa \\
Bone class (A/C) & $1=$ mucous retention cyst \\
Residual bone height (mm) & $40(52.6 \%) / 36(47.4 \%)$ \\
Septa & $3.7 \pm 1.5$ \\
Posterior superior alveolar artery passing & $4(5.3 \%)$ \\
through the osteotomy area & $10(13.2 \%)$ \\
\hline
\end{tabular}

Sex, age, periodontal disease, hypertension, bone class, and $\mathrm{RBH}$ did not influence the analgesics intake (Table 3). VAS values, discomfort level, and willingness were not influenced by any of the patient-related factors except for bone class $\mathrm{C}$ patients who experienced a statistically significantly higher discomfort during surgery $(p=0.032)$ (Table 4$)$.

Complications and success rates Surgical complications included 4 membrane perforations (5.26\%), while healing complications included 2 wounds healed slightly by secondary intention $(2.63 \%)$, giving a total complication rate of $7.89 \%$.

In all cases of membrane perforation, the post-surgical OPT x-rays exam performed showed the graft well contained under the sinus membrane, as well as the CBCT X-rays exam performed at 6 months. During the follow-up visits, these patients did not show any signs or symptoms of sinusitis or infection, which were accurately investigated. Patients with secondary intention wound healing were visited weekly until complete healing. In the meanwhile, they were asked to continue with cold and soft/liquid diet and rinse twice a day with a $0.12 \%$ chlorhexidine solution until complete healing which occurred in all cases within the third and fourth week after surgery.

All patients showed in CBCT an adequate bone volume after 6 months allowing to place the planned implants in the correct position and axis. No complications or adverse reactions were observed during implant surgery. At re-entry surgery, all implants were successfully osseointegrated and successively loaded, giving an osseointegration rate of $100 \%$.

\section{Discussion}

The main objective of this study was to evaluate data about PROMs following LSFE and to investigate association with influencing factors. PROMs are useful tools that help the clinician to obtain information on the patient's experience and on certain aspects following interventions such as symptoms, condition, and overall quality of life. These data may concur to the decision-making process and provide the patient adequate information about risk factors, post-operative experience, and recovery after surgery, definitely providing an optimal and adequate oral health treatment.

LSFE is considered a quite invasive technique. Discomfort during surgery is generally quite mild, while post-surgical pain, swelling, and ecchymosis are the most common observed signs and symptoms. Nevertheless, to date, only little piece of literature has explored this field [8, 30, 34, 35].

In the present study, post-surgical pain was evaluated by the patients through a $0-10$ points VAS during the week following LSFE. Secondary outcomes were: discomfort experienced during surgery, willingness to undergo the same 
Table 2 Average pain VAS values reported over the 7 days of observation of the entire population and stratified by groups based on sex (SEX), smokers (SMK), hypertension (HYP), residual bone height $(\mathrm{RBH})$, and periodontal disease (PER). Significant intergroup differences are marked in italic. For each value, mean, standard deviation (SD), interquartile range (IQR), median, and the range of values were reported, indicating the minimum and maximum (min; max)

\begin{tabular}{|c|c|c|c|c|c|c|c|c|c|c|}
\hline & & \multicolumn{2}{|l|}{ Vas 1} & \multicolumn{2}{|l|}{ Vas 2} & \multicolumn{3}{|c|}{ Vas 3} & \multicolumn{2}{|l|}{ Vas 4} \\
\hline & & Mean $\pm \mathrm{SD} ;(\mathrm{IQR})$ & $\begin{array}{l}\text { Median } \\
(\min ; \max )\end{array}$ & Mean $\pm \mathrm{SD}$; (IQR) & $\begin{array}{l}\text { Median } \\
\text { (min; max) }\end{array}$ & \multicolumn{2}{|c|}{ Mean $\pm \mathrm{SD} ;(\mathrm{IQR})$} & $\begin{array}{l}\text { Median } \\
\text { (min; max) }\end{array}$ & Mean $\pm \mathrm{SD}$; (IQR) & $\begin{array}{l}\text { Median } \\
\text { (min; max) }\end{array}$ \\
\hline \multirow{2}{*}{\multicolumn{2}{|c|}{ Total population }} & \multirow[t]{2}{*}{$5.07 \pm 2.13 ;(2.5)$} & \multirow[t]{2}{*}{$5(0 ; 10)$} & \multirow[t]{2}{*}{$4.37 \pm 2.52 ;(3)$} & \multirow[t]{2}{*}{$5(0 ; 10)$} & \multicolumn{2}{|c|}{$3.27 \pm 2.41$ (4) } & $3(0 ; 8)$ & \multirow[t]{2}{*}{$1.94 \pm 2.06(3)$} & \multirow[t]{2}{*}{$1(0 ; 8)$} \\
\hline & & & & & & & & & & \\
\hline & M & & $5(0 ; 10)$ & $4.15 \pm 2.73 ;(3)$ & $5(0 ; 10)$ & $2.91 \pm$ & $3 ;(4)$ & $2.5(0 ; 8)$ & $2.01 \pm 2.33$ & $1(0 ; 7.5)$ \\
\hline & $\mathrm{F}$ & $5.03 \pm 2.03 ;(1.5)$ & $5.15(5 ; 10)$ & $4.59 \pm 2.03 ;(2)$ & $5(0 ; 9)$ & $3.63 \pm$ & $7 ;(3.5)$ & $4(0 ; 8)$ & $1.87 \pm 1.78 ;(1.3)$ & $1.4(0 ; 8)$ \\
\hline & $p$ value & 0.8953 & & 0.3196 & & 0.148 & & & 0.6039 & \\
\hline SMK & $\mathrm{Y}$ & $5.91 \pm 2.11 ;(2)$ & $6(1 ; 10)$ & $4.92 \pm 2.80 ;(2)$ & $5(0 ; 10)$ & $3.96 \pm$ & $7 ;(5)$ & $4.5(0 ; 8)$ & $2.09 \pm 2.18 ;(3.5)$ & $1.35(0 ; 6)$ \\
\hline & $\mathrm{N}$ & $4.81 \pm 2.09 ;(2)$ & $5(0 ; 9)$ & $4.20 \pm 2.43 ;(3)$ & $5(0 ; 9)$ & $3.06 \pm$ & $7 ;(4)$ & $3(0 ; 8)$ & $1.89 \pm 2.04 ;(2.3)$ & $1(0 ; 8)$ \\
\hline & $p$ value & 0.0642 & & 0.3893 & & 0.218 & & & 0.8033 & \\
\hline HYP & $\mathrm{Y}$ & $5.68 \pm 1.85 ;(2.69)$ & $2.39(1 ; 7)$ & $4.43 \pm 2.86 ;(4.4)$ & $5(0 ; 9)$ & $3.58 \pm$ & $9 ;(4.65)$ & $3.75(0 ; 8)$ & $2.45 \pm 2.57 ;(3.65)$ & $1.85(0 ; 8)$ \\
\hline & $\mathrm{N}$ & $4.95 \pm 2.17 ;(2)$ & $5(0 ; 10)$ & $4.36 \pm 2.48 ;(3)$ & $5(0 ; 10)$ & $3.21 \pm$ & $3 ;(4)$ & $3(0 ; 8)$ & $1.84 \pm 1.96 ;(2.65)$ & $1(0 ; 7.5)$ \\
\hline & $p$ value & 0.2254 & & 0.6912 & & 0.768 & & & 0.5517 & \\
\hline RBH & $<5$ & $5.29 \pm 2.25 ;(2)$ & $5(0 ; 10)$ & $4.68 \pm 2.59 ;(2)$ & $5(0 ; 10)$ & $3.45 \pm$ & $5 ;(4)$ & $3.5(0 ; 8)$ & $1.91 \pm 2.24 ;(2.5)$ & $1(0 ; 7.5)$ \\
\hline & & $4.87 \pm 2.03 ;(2.35)$ & $5(0 ; 9)$ & $4.09 \pm 2.46 ;(3.5)$ & $5(0 ; 9)$ & $3.11 \pm$ & $1 ;(4)$ & $3(0 ; 8)$ & $1.97 \pm 1.92 ;(2.75)$ & $2(0 ; 8)$ \\
\hline & $p$ value & 0.3983 & & 0.7825 & & 0.068 & & & 0.1261 & \\
\hline PER & $\mathrm{Y}$ & $5.03 \pm 2.17 ;$ & $6(0 ; 10)$ & $4.1 \pm 3.06 ;(6)$ & $5(0 ; 10)$ & $3.18 \pm$ & ; (5) & $3(0 ; 8)$ & $1.95 \pm 2.25 ;(3)$ & $1(0 ; 7.5)$ \\
\hline & $\mathrm{N}$ & $5.09 \pm 1.67 ;(2)$ & $5(1 ; 9)$ & $4.54 \pm 2.12 ;(3)$ & $5(0 ; 9)$ & $3.33 \pm$ & $4 ;(3.5)$ & $3(0 ; 8)$ & $1.93 \pm 1.95 ;(1.8)$ & $1.4(0 ; 8)$ \\
\hline & $p$ value & 0.4641 & & 0.7588 & & 0.715 & & & 0.6649 & \\
\hline BCL & & $5.35 \pm 2.38 ;(2.75)$ & $5(0 ; 10)$ & $4.54 \pm 2.8 ;(3)$ & $5(0 ; 10)$ & $3.29 \pm$ & 4; (4) & $3(0 ; 8)$ & $1.99 \pm 2.1 ;(2.7)$ & $2(0 ; 8)$ \\
\hline & & $4.76 \pm 1.99 ;(2.5)$ & $5(0 ; 7)$ & $4.18 \pm 2.20 ;(3)$ & $5(0 ; 7)$ & $3.25 \pm$ & $9 ;(4)$ & $3.5(0 ; 7.7)$ & $1.88 \pm 2.04 ;(3)$ & $1(0 ; 7.5)$ \\
\hline & $p$ value & 0.4671 & & 0.6201 & & 0.979 & & & 0.8114 & \\
\hline & & Vas 5 & & & s 6 & & & Vas 7 & & \\
\hline & & Mean \pm SD; (IC & QR) & $\begin{array}{l}\text { Median } \\
(\min ; \max )\end{array}$ & ean $\pm \mathrm{SD}$; (IQI & & $\begin{array}{l}\text { Median } \\
\text { (min; max) }\end{array}$ & Mean & $\mathrm{n} \pm \mathrm{SD} ;(\mathrm{IQR})$ & $\begin{array}{l}\text { Median } \\
\text { (min; max) }\end{array}$ \\
\hline $\begin{array}{l}\text { Total p. } \\
\text { Variab. }\end{array}$ & pulation & $1.10 \pm 1.83(2)$ & & $0(0 ; 9.5)$ & $1 \pm 1.58(0)$ & & $0(0 ; 9.5)$ & $0.36 \pm$ & $=1.27(0)$ & $0(0 ; 9.5)$ \\
\hline Sex & & $1.07 \pm 1.95(2)$ & & $0(0 ; 9.5)$ & $1 \pm 1.71 ;(0)$ & & $0(0 ; 9.5)$ & $0.47 \pm$ & $=1.63 ;(0)$ & $0(0 ; 9.5)$ \\
\hline & & $1.14 \pm 1.72 ;(2)$ & & $0(0 ; 6)$ & $1 \pm 1.48 ;(0)$ & & $0(0 ; 6.5)$ & $0.28 \pm$ & $=0.77 ;(0)$ & $0(0 ; 4)$ \\
\hline & & 0.4977 & & & 878 & & & 0.6350 & & \\
\hline SMK & & $1.09 \pm 1.65 ;(2)$ & & $0(0 ; 5.6)$ & $7 \pm 1.58 ;(0)$ & & $0(0 ; 6.5)$ & $0.06 \pm$ & $=0.24 ;(0)$ & $0(0 ; 1)$ \\
\hline & & $1.11 \pm 1.89 ;(2)$ & & $0(0 ; 9.5)$ & $5 \pm 1.60 ;(0)$ & & $0(0 ; 9.5)$ & $0.46 \pm$ & $=1.43 ;(0)$ & $0(0 ; 9.5)$ \\
\hline & & 0.9619 & & & 289 & & & 01599 & & \\
\hline HYP & & $1.72 \pm 2.21 ;(2.75)$ & & $0.75(0 ; 6)$ & $3 \pm 2.26 ;(2.25)$ & & $0(0 ; 6.5)$ & $0.71 \pm$ & $=1.36 ;(1)$ & $0(0 ; 4)$ \\
\hline & & $0.99 \pm 1.74 ;(2)$ & & $0(0 ; 9.5)$ & $7 \pm 1.41 ;(0)$ & & $0(0 ; 9.5)$ & $3 \pm 12$ & $5 ;(0)$ & $0(0 ; 9.5)$ \\
\hline & & 0.1818 & & & 425 & & & 0.2476 & & \\
\hline RBH & & $1.17 \pm 2.17 ;(1)$ & & $0(0 ; 9.5)$ & $9 \pm 1.59 ;(0)$ & & $0(0 ; 9.5)$ & $0.42 \pm$ & $=1.76 ;(0)$ & $0(0 ; 9.5)$ \\
\hline & & $1.04 \pm 1.47 ;(2)$ & & $0(0 ; 6)$ & $6 \pm 1.13 ;(2.5)$ & & $0(0 ; 50)$ & $0.43 \pm$ & $=0.9 ;(0.25)$ & $0(0 ; 4)$ \\
\hline & & 0.2328 & & & 432 & & & 0.4974 & & \\
\hline PER & & $1.03 \pm 1.96 ;(2)$ & & $0(0 ; 9.5)$ & $8 \pm 1.82 ;(0)$ & & $0(0 ; 9.5)$ & $0.42 \pm$ & $=1.76 ;(0)$ & $0(0 ; 9.5)$ \\
\hline & & $1.15 \pm 1.75 ;(2)$ & & $0(0 ; 6)$ & $9 \pm 1.42 ;(5)$ & & $0(0 ; 6.5)$ & $0.33 \pm$ & $=0.82 ;(0)$ & $0(0 ; 4)$ \\
\hline & & 0.6825 & & & 133 & & & 0.2991 & & \\
\hline BCL & & $1.28 \pm 1.73 ;(2)$ & & $0(0 ; 6)$ & $\pm 1.15 ;(0)$ & & $0(0 ; 5)$ & $0.32 \pm$ & $=0.85 ;(0)$ & $0(0 ; 4)$ \\
\hline & & $0.91 \pm 1.93 ;(1)$ & & $0(0 ; 9.5)$ & $3 \pm 1.97 ;(0)$ & & $0(0 ; 9.5)$ & $0.41 \pm$ & $=1.62 ;(0)$ & $0(0 ; 9.5)$ \\
\hline & & 03043 & & & 821 & & & 0.6759 & & \\
\hline
\end{tabular}

surgery, onset and duration of swelling and ecchymosis, analgesics intake, and complications rate.

The recent systematic review by Younes et al. [30] analyzed 11 studies about PROMs after LSFE. Unfortunately, due to the high heterogeneity in study design (1 cohort study; 1 retrospective case series; 2 prospective case series; 7 randomized controlled trials), graft materials and evaluation of outcome variables, only a descriptive data analysis was provided. The review included studies in which either uni-lateral, or bi-lateral or both sinus lift procedures were performed. The number of subjects included in most of the studies was generally very low: 9 studies enrolled less than 40 patients. Data regarding pain was reported in 8 of the 11 studies, using a 0 10 [36, 37] or 0-100 VAS [38, 39], or 3- to 5-point scales [33, 40-42]. Pain was evaluated for 7 days in all studies, with the exception of Ozturan et al. (4 days) [39], Deppe et al. [33], (14 days), Nickenig et al. (day of the surgery, 1 st and 7 th postsurgical day) [36], and Farina et al.(first week and 14th day) [34]. In the study of Pieri et al. [42], PROMs were evaluated only after the reconstructive procedure and implant 


\section{SEVERE / NON SEVERE PAIN}

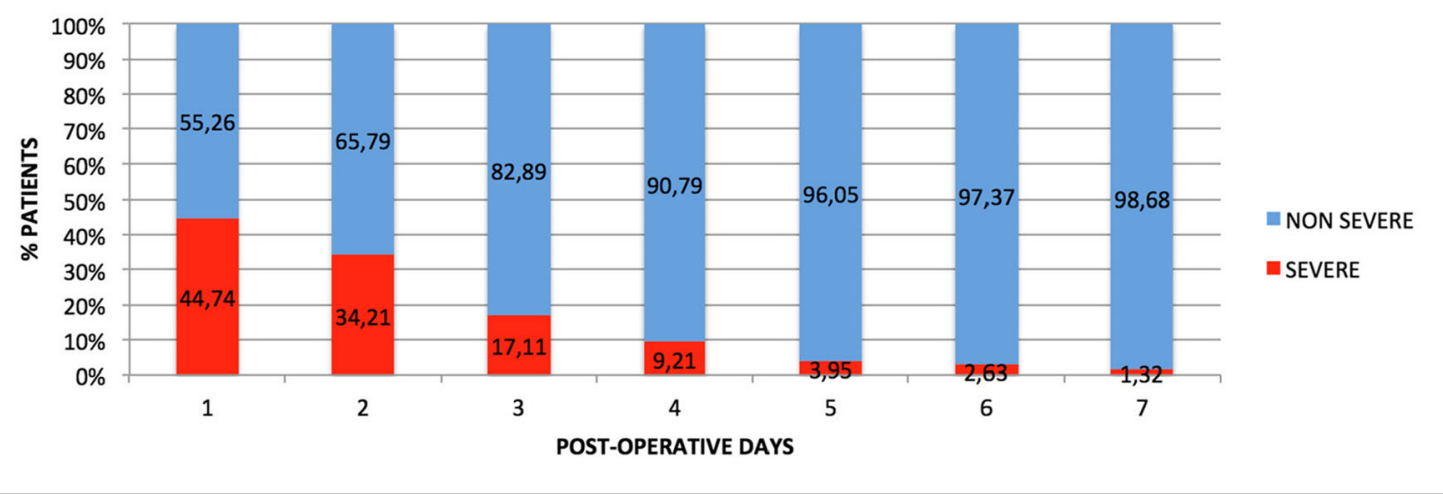

Fig. 1 Distribution of severe pain and non-severe pain during the first post-operative week

placement. The inclusion of this article in a review analyzing PROMs after LSFE is quite questionable. Edema was documented in only 4 studies [38, 40-42]. Among other outcome measures, some studies also reported on the ability to eat and work, and phonetics [38, 40, 41], bleeding, sleeping [38, 40], and the breathing capability [38]. Mardinger et al. used two combined and adjusted Health-Related Quality Of Life (HRQOL) questionnaires for all evaluations [41]. An Oral Health Impact Profile-14 (OHIP-14) was used in 1 study to assess patient satisfaction [39].

Our findings indicate that post-operative pain has moderate values in the first 2 days with a gradual decline until the 7th day. From the 5th day, the median was 0 ; however, on the 7th day, still $15.78 \%$ of patients suffered pain, similarly to what observed by Mardinger et al. (11.8\%) [41], suggesting to extend the reporting period in future studies. These findings are in line with previous studies that showed a pain peak on the day of surgery or first post-operative day followed by a gradual decrease in the following [30, 36-41] Conversely, in the study of Merli et al. [37], pain VAS values reported, after a one-stage LSFE procedure with conscious sedation, were very low (lower than 2 on a $0-10$ scale), but with a different and conflicting trend (day $1: 1.5 \pm 1.7$; day $2: 1.0 \pm 1.3$; day $3: 0.9$ \pm 1.5 ; day 4: $1.2 \pm 2.0$; day $5: 1.3 \pm 2.1$; day $6: 1.2 \pm 1.9$ ). Similarly in a study comparing lateral or trans-crestal approach, both procedures resulted in very low pain VAS values, lower than 25 on a $0-100$ scale, with higher values for the trans-crestal approach [34].

In the present article, beyond mean and median pain VAS values, also the prevalence of severe pain (VAS value $>50$ ) was provided, observing that severe pain until the 7th day was reported by one patient only. This information is clinically relevant, but to date, only a study provided it, showing that $90 \%$ of patients experienced pain but only $8 \%$ had severe pain [33].

For comparison, this surgical intervention has shown to determine lower morbidity than the mandibular third molar extraction, except for swelling [41]. It should be taken into account that third molar extraction is usually performed in younger patients [43], with different psychological attitude and biological conditions that may influence pain experience and recovery time.

In the present study, no differences in pain based on age or gender were observed, in agreement with most of the articles in literature except for a study, in which female patients experienced more pain [41]. It should be considered that there might be other factors that can influence pain, which do not depend on the patient, but on the study design and surgical protocol.

In this study, painkillers assumption (ibuprofen $600 \mathrm{mg}$ ) in the days following surgery was self-administered by patients. A similar protocol was adopted in some studies with changes in dosage $(600 \mathrm{mg}$ or $400 \mathrm{mg}$ ) $[34,36,38]$ or medication (paracetamol $500 \mathrm{mg}$ ) [39]. In the study of Farina et al., dexamethasone i.m. was given in addition to ibuprofen $600 \mathrm{mg}$ [34]. In other studies, painkillers were prescribed (ibuprofen or paracetamol) for 3 to 4 days after surgery regardless of pain $[37,40]$, or in combination with conscious sedation and intravenous administration of tramadol $100 \mathrm{mg}$, ketorolac $30 \mathrm{mg}$, and betamethasone sodium phosphate $4 \mathrm{mg}$ [37]. Other studies did not clearly describe the drug protocol [44] [41].

The morbidity of this surgical procedure is lower than other GBR ones, and this may probably depend on the reduced surgical time, and on the management of soft tissues, without periosteal releasing incisions, and with closure by primary intention.

Regarding surgical time, it could significantly influence the levels of pain and discomfort during surgery [45]. It depends on several variables such as operator skills, the occurrence of intrasurgical complications, the use of piezoelectric devices or rotary instruments [34, 40], or autologous bone grafting [37].

Also the size of the osteotomy could affect pain levels and surgical time in a reciprocal way. A smaller osteotomy initially requires less time, but however it can lead to greater difficulties in lifting the sinus membrane, with consequent 


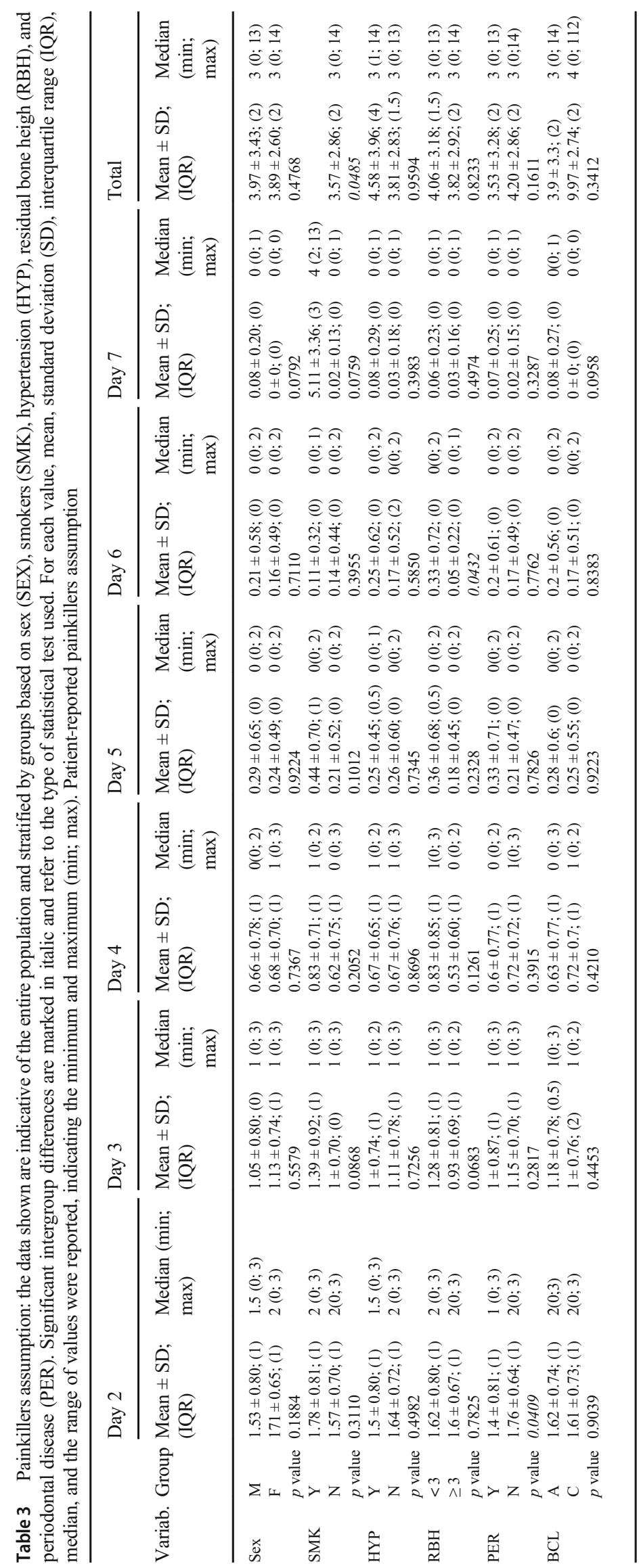




\section{PAINKILLERS ASSUMPTION}

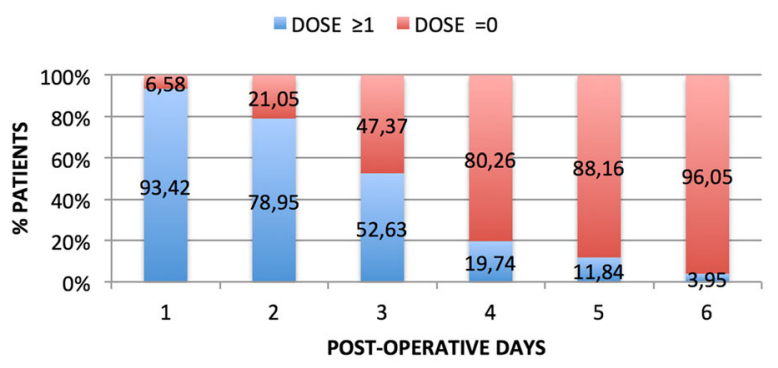

Fig. 2 Relative percentages of patient's painkillers assumption

increase in surgical time and possible intra-surgical complications. In the present study, we adopted a relatively small osteotomy dimension, similarly to Farina et al. [34].

The flap design should be strongly taken into account. It was observed that flap elevation made with two vertical incisions (trapezoidal flap design) gave more pain and swelling than one incision (triangular flap design) [29]. Among the studies considered, the flap design was very $[34,37,38]$ or not clearly specified [39-41].

With regard to the discomfort during surgery, in the present study, it was very low. Patients who had major surgical discomfort had also experienced more pain. This remarks how surgical experience affects the perception of pain and vice versa. Post-operative discomfort can be effectively alleviated or even eliminated through various conscious or moderate sedation procedures $[37,46,47]$. The evaluation of discomfort during surgery is clinically very relevant, because it helps the clinician to communicate to the patient what really awaits him during the surgery.
As well as discomfort, the willingness to undergo the same surgery again was also very high (77.63\% of patients). We found only a study reporting on it, with a definitely lower outcome (50\%) [34]. A certain relationship between willingness and pain can be hypothesized, since patients from the present study, who had a lot of pain the day after the surgery and on days 5 and 7 , expressed low willingness to undergo the same surgery.

Regrettably, swelling was the most evident sign $(97.36 \%$ of patients). We must point out that this parameter is difficult to assess in a quantitative or qualitative way, and generally, it is assessed subjectively by the patient, as well as ecchymosis. We found an article that attempted a quantitative evaluation through an optical 3-D imaging analysis for facial volumetric changes [36]. In an another study, the distance between the gonion and the external canthus of the eye was measured [39]. Scarano et al. used thermal infrared imaging [29].

Our observations regarding swelling were comparable to previous researches. Del Fabbro et al. observed the highest level of swelling on the 1st post-surgical day, with a gradual decline until 7th day. Delilbasi et al., observed highest values at $36 \mathrm{~h}$, with a gradual decline thereafter. Mardinger et al. reported a median value of 5 (on a $0-5$ VRS) on the 2 nd day after surgery, with a decline until the 7 th day on which $21 \%$ of patients still reported swelling. Farina et al. observed a peak on days 1 and 2 with a gradual decline up to the 7th day. Scarano et al. observed a mean value of $3.27 \pm 0.59$ (on a 0 5 VRS) on the 2 nd day and reduced values until the 6th day, reaching no swelling at 14 days.

We have found correlation between swelling and pain. It should be considered that anti-edema drugs, such as corticosteroids, have not been used, as well as painkillers were prescribed ad libitum, to prevent post-surgical medications from

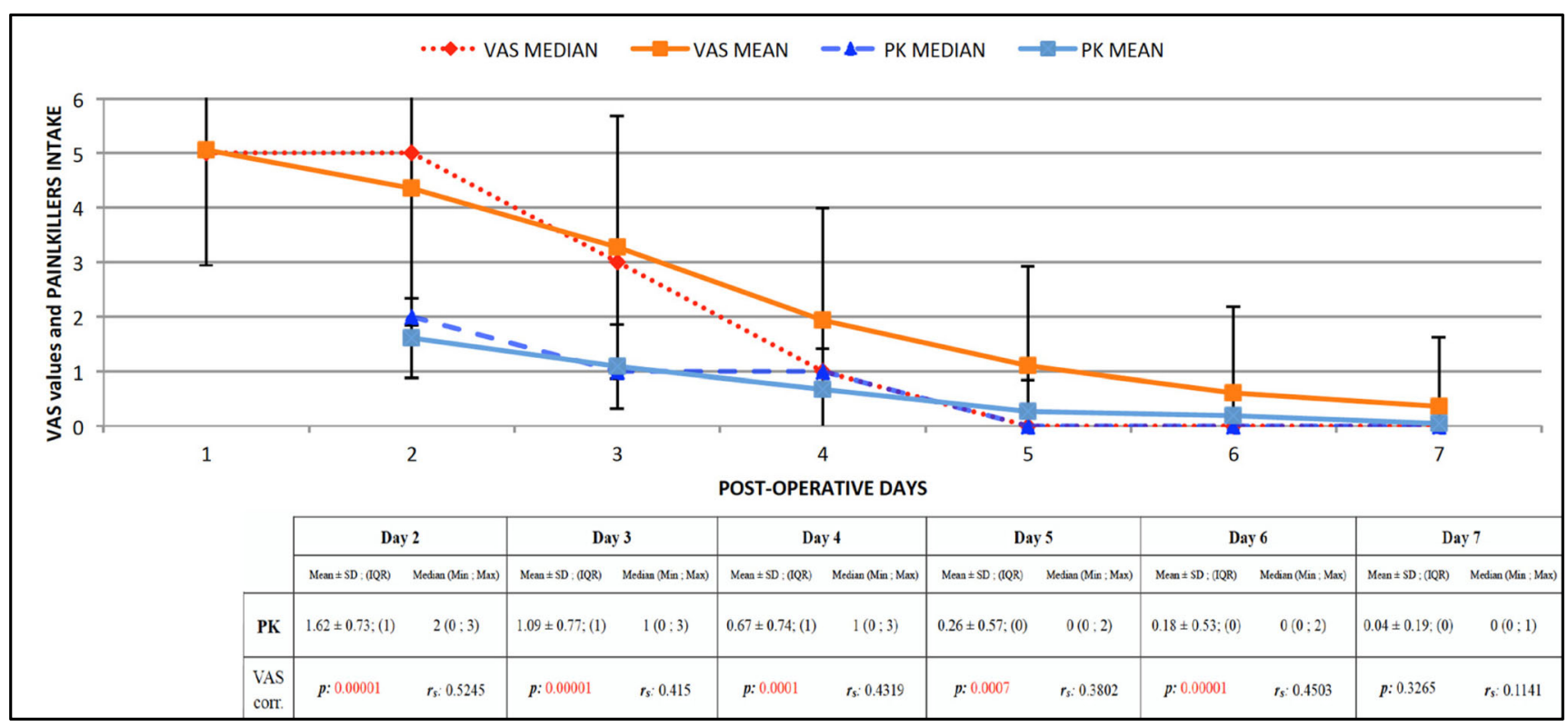

Fig. 3 Pain VAS values and painkillers assumption during the first post-operative week 
Table 4 Patient-reported discomfort level. Table 4 Discomfort: patient discomfort levels are reported as probability distributions and mean difference in the different groups. The data shown are indicative of the entire population and stratified by groups based on sex (SEX), smokers (SMK), hypertension (HYP), residual bone heigh (RBH), and periodontal disease (PER). Significant intergroup differences are marked in italic and refer to the type of statistical test used. For each value, mean, standard deviation (SD), interquartile range (IQR), median, and the range of values were reported, indicating the minimum and maximum (min; max)

\begin{tabular}{|c|c|c|c|c|c|c|c|}
\hline \multirow[b]{2}{*}{ SUB } & \multirow[b]{2}{*}{ Total } & \multicolumn{5}{|c|}{$\begin{array}{lcc}0 & 1 & 2 \\
\mathrm{~N}^{\circ} \text { of subjects (relative percentage) }\end{array}$} & \multirow{2}{*}{$\begin{array}{l}\text { Intergroup difference (Mann-Whitney) } \\
\text { Mean } \pm \text { SD; (IQR)-median (min; max) } \\
0.79 \pm 1.01 ;(1)-1(0 ; 4)\end{array}$} \\
\hline & & $37(48.68)$ & $26(34.21)$ & $8(10.53)$ & $2(2.63)$ & $3(3.95)$ & \\
\hline \multirow[t]{3}{*}{ SEX } & M & $16(42.1)$ & $16(42.11)$ & $3(7.89)$ & $1(2.63)$ & $2(5.26)$ & $0.87 \pm 1.04 ;(1)-1(0 ; 4)$ \\
\hline & $\mathrm{F}$ & $21(55.26)$ & $10(26.32)$ & $5(13.16)$ & $1(2.63)$ & $1(2.63)$ & $0.71 \pm 0.98 ;(1)-0(0 ; 4)$ \\
\hline & Fisher's exact test & & & 0.5720 & & & 0.4026 \\
\hline \multirow[t]{3}{*}{ SMK } & $\mathrm{Y}$ & $9(50)$ & $7(38.89)$ & $0(0)$ & $0(0)$ & $2(11.11)$ & $0.83 \pm 1.24 ;(1)-0.5(0 ; 4)$ \\
\hline & $\mathrm{N}$ & $28(48.28)$ & $19(32.76)$ & $8(6.1)$ & $2(3.45)$ & $1(1.72)$ & $0.78 \pm 0.94 ;(1)-1(0 ; 4)$ \\
\hline & Fisher's exact test & & & 0.3650 & & & 0.8056 \\
\hline \multirow[t]{3}{*}{ HYP } & $\mathrm{Y}$ & $6(50.00)$ & $3(25.00)$ & $1(8.33)$ & $1(8.33)$ & $1(8.33)$ & $1 \pm 1.37 ;(1.5)-0.5(0 ; 4)$ \\
\hline & $\mathrm{N}$ & $31(48.44)$ & $23(35.94)$ & $7(10.94)$ & $1(1.56)$ & $2(3.12)$ & $0.75 \pm 0.94 ;(1)-1(0 ; 4)$ \\
\hline & Fisher's exact test & & & 0.3650 & & & 0.8056 \\
\hline \multirow[t]{3}{*}{$\mathrm{RBH}$} & $<3$ & $19(52.78)$ & $10(27.78)$ & $5(13.89)$ & $0(0)$ & $2(5.56)$ & $0.78 \pm 1.07 ;(1)-0(0 ; 4)$ \\
\hline & $>3$ & $18(45.00)$ & $16(40.00)$ & $3(7.50)$ & $2(5.00)$ & $1(2.50)$ & $0.8 \pm 0.97 ;(1)-1(0 ; 4)$ \\
\hline & Fisher's exact test & & & 0.4650 & & & 0.718 \\
\hline \multirow[t]{3}{*}{ PER } & $\mathrm{Y}$ & $11(36.67)$ & $13(43.33)$ & $4(13.33)$ & $0(0)$ & $2(6.67)$ & $0.97 \pm 1.07 ;(1)-1(0 ; 4)$ \\
\hline & $\mathrm{N}$ & $26(56.52)$ & $13(28.26)$ & $4(8.70)$ & $2(4.35)$ & $1(2.17)$ & $0.67 \pm 0.97 ;(1)-0(0 ; 4)$ \\
\hline & Fisher's exact test & & & 0.2540 & & & 0.1310 \\
\hline \multirow[t]{3}{*}{$\mathrm{BCL}$} & A & $21(52.5)$ & $13(32.5)$ & $1(2.5)$ & $2(5)$ & $3(7.5)$ & $0.83 \pm 0.12 ;(1)-0(0 ; 4)$ \\
\hline & $\mathrm{C}$ & $16(44.44)$ & $13(36.11)$ & $7(19.44)$ & $0(0)$ & $0(0)$ & $0.07 \pm 0.08 ;(1)-1(0 ; 2)$ \\
\hline & Fisher's exact test & & & 0.0320 & & & 0.5945 \\
\hline
\end{tabular}

being confounding factors. For this reason, the comparison of our findings with other studies in the literature is difficult and must be interpreted taking into account that the post-surgical instructions are very variable or not clearly defined $[12,33]$. In the study of Schwartz-Arad et al., dexamethasone was prescribed, but swelling and hematoma were very frequent [48]. Pieri et al. prescribed betamethasone in addition to ibuprofen and reported a low prevalence of edema [42]. No corticosteroids were prescribed by Scarano et al., but Ibuprofen was prescribed to all patients for 3 days [29]. Edema was reported by only $1.6 \%$ of patients by Moreno et al. including dexamethasone in the anesthetic induction and oral non-steroidal anti-inflammatory drugs and analgesics were prescribed to all patients for 8 days [9].

Ecchymosis, which is not often reported in literature, was found in only $51.32 \%$ of the patients in our study. Those who had early bruising had less pain afterwards. Similar results were observed by Merdinger et al. (56\%) [41]. In a study in which plasma rich in growth factors was used, ecchymosis was experienced by $60 \%$ of patients [38]. From our experience and from the open comments left by the patients, bruising does not particularly bothers the patient. If properly advised about this possibility, patients accept it well.
Regarding complications after LSFE, the most frequent is membrane perforation, followed by ostium obstruction and infections [48]. Membrane perforation has some clinical implications such as increased susceptibility to infections or an inadequately contained graft and may influence the implant survival rate [49]. In the present study, we did not find severe healing complications and, compared to other studies $[9,27$, $28,40,48-53]$, a very low percentage of surgical complications: only 4 membrane perforations (5.2\%). It should be emphasized that in this study, patient selection, accurate diagnosis, and careful therapeutic planning were scrupulously aspired. The use of a sonic device is undoubtedly another reason that could justify these findings, as reported in a recent metaanalysis [27]. Also the experience of the surgeon is crucial.

The major limit of this study was intrinsic to the aim itself, that is, measuring something like pain and discomfort, which are subjective variables, difficult to objectively quantify, as well as swelling. Another limitation is the design of the study, as it lacks a control group and therefore it was not possible to apply a randomization.

Not having adopted standard measurement systems such as OHIP-14 or OHRQOL, limits the comparison of the findings obtained with some present in the literature. We believe that these systems were not adequate for the specific topic covered, 
Table 5 Relationship between VAS pain values and willingness/ discomfort level. Table 5 Relationship between VAS pain values and willingness/discomfort levels: pain VAS values at different levels of discomfort (D) and willingness (W) in the 7 days of observation.
Significant intergroup differences were marked in italic and were calculates by Kruskal-Wallis $\mathrm{H}$ test. For each level of D and W, the number of patients with correspondence of the VAS value indicated as median, interquartile range (IQR), and range (min; max) was reported

\begin{tabular}{|c|c|c|c|c|c|c|c|c|c|c|c|c|c|c|c|c|}
\hline \multirow{3}{*}{$\begin{array}{l} \\
\mathrm{D}\end{array}$} & \multirow{3}{*}{$\begin{array}{l}\text { Level } \\
0\end{array}$} & \multirow{3}{*}{$\frac{\mathrm{N}^{\circ}}{37}$} & \multirow{2}{*}{\multicolumn{2}{|c|}{$\begin{array}{l}\text { VAS } 1 \\
\begin{array}{l}\text { Median-IQR } \\
\text { (min; max) }\end{array}\end{array}$}} & \multirow{2}{*}{\multicolumn{2}{|c|}{$\begin{array}{l}\text { VAS } 2 \\
\begin{array}{l}\text { Median-IQR } \\
\text { (min; max) }\end{array}\end{array}$}} & \multirow{2}{*}{\multicolumn{2}{|c|}{$\begin{array}{l}\text { VAS } 3 \\
\begin{array}{l}\text { Median-IQR } \\
\text { (min; max) }\end{array}\end{array}$}} & \multirow{2}{*}{\multicolumn{2}{|c|}{$\begin{array}{l}\text { VAS } 4 \\
\begin{array}{l}\text { Median-IQR } \\
\text { (min; max) }\end{array}\end{array}$}} & \multirow{2}{*}{\multicolumn{2}{|c|}{$\begin{array}{l}\text { VAS } 5 \\
\begin{array}{l}\text { Median-IQR } \\
\text { (min; max) }\end{array}\end{array}$}} & \multirow{2}{*}{\multicolumn{2}{|c|}{$\begin{array}{l}\text { VAS } 6 \\
\begin{array}{l}\text { Median-IQR } \\
\text { (min; max) }\end{array}\end{array}$}} & \multirow{2}{*}{\multicolumn{2}{|c|}{$\begin{array}{l}\text { VAS } 7 \\
\begin{array}{l}\text { Median-IQR } \\
\text { (min; max) }\end{array}\end{array}$}} \\
\hline & & & & & & & & & & & & & & & & \\
\hline & & & 5 & $1(0 ; 8)$ & 5 & $2(0 ; 8)$ & 3 & $4(0 ; 8)$ & 1 & $2(0 ; 6)$ & 0 & $1(1 ; 5.6)$ & 0 & $0(0 ; 6.5)$ & 0 & $0(0 ; 1)$ \\
\hline & 1 & 26 & 5 & $3.5(0 ; 8)$ & 5 & $3(0 ; 7)$ & 3.5 & $3(0 ; 7)$ & 1.5 & $3(0 ; 6)$ & 0 & $2(0$ & 0 & $2(0$ & 0 & $0(0 ; 2)$ \\
\hline & 2 & 8 & 4 & $5(5 ; 7)$ & 2.5 & $5.6(0 ; 65)$ & 1.8 & $3.3(0 ; 5)$ & 1.6 & $3.5(0 ; 7.5)$ & 0.6 & $3(0 ;$ & 0.6 & $2.5(0 ; 9.5)$ & 0 & $1.6(0 ; 9.5$ \\
\hline & 3 & 2 & 4.3 & $4.5(2 ; 6.5)$ & 3.3 & $6.5(0 ; 65)$ & 2.3 & $4.5(0 ; 4.5)$ & 2.3 & $4.5(0 ; 4.5)$ & 1.8 & $3.5(0 ; 3.5)$ & 1.3 & $2.5(0 ; 2.5)$ & 1.3 & $2.5(0 ; 2.5)$ \\
\hline & 4 & 3 & 10 & $1(9 ; 10)$ & 10 & $1(9 ; 10)$ & 8 & $0(8 ; 8)$ & 6 & $20(6 ; 8)$ & 3 & $3(3 ; 6)$ & 0 & $5(0 ; 5)$ & 0 & $4(0 ; 4)$ \\
\hline & \multicolumn{2}{|c|}{$p$ value } & \multicolumn{2}{|c|}{0.0425} & \multicolumn{2}{|c|}{0.0481} & \multicolumn{2}{|c|}{0.0259} & \multicolumn{2}{|c|}{0.0518} & \multicolumn{2}{|c|}{0.0585} & \multicolumn{2}{|c|}{0.0762} & \multicolumn{2}{|c|}{0.0401} \\
\hline \multirow{5}{*}{ W } & 0 & 59 & 5 & $2(0 ; 8)$ & 5 & $3(0 ; 8)$ & 3 & $4(0 ; 7.7)$ & 1 & $2(0 ; 7.5)$ & 0 & $1(0 ; 9.5)$ & 0 & $0(0 ; 9.5)$ & 0 & $0(0 ; 9.5)$ \\
\hline & 1 & 12 & 6 & $4.5(0.5 ; 8)$ & 5.5 & $4.5(0 ; 8)$ & 4.5 & $4.5(0 ; 8)$ & 2.5 & $4 ;(0 ; 6)$ & 1 & $3.5(0 ; 5)$ & 0 & $2(0 ; 3)$ & 0 & $0(0 ; 1)$ \\
\hline & 2 & 1 & 3 & $0(3 ; 3)$ & 3 & $0(3 ; 3)$ & 1.5 & $0(1.5 ; 1.5)$ & 0 & $0(0 ; 0)$ & 0 & $0(0 ; 0)$ & 0 & $0(0 ; 0)$ & 0 & $0(0 ; 0)$ \\
\hline & 3 & 4 & 9.5 & $30(5 ; 10)$ & 9.5 & $5.1(0.8 ; 10)$ & 8 & $3.6(0.9 ; 8)$ & 6 & $3.5(1.1 ; 8)$ & 3 & $2.4(1.2 ; 6)$ & 0.6 & $3.1(0 ; 5)$ & 0.6 & $2.6(0 ; 4)$ \\
\hline & \multicolumn{2}{|c|}{$p$ value } & \multicolumn{2}{|c|}{0.0450} & \multicolumn{2}{|c|}{0.189} & \multicolumn{2}{|c|}{0.1208} & \multicolumn{2}{|c|}{0.0241} & \multicolumn{2}{|c|}{0.0104} & \multicolumn{2}{|c|}{0.2101} & \multicolumn{2}{|c|}{0.2236} \\
\hline
\end{tabular}

but too generic and unable to focus on the type of intervention performed. However, we have adopted a large number of measurements, hard to find in most of the studies at the moment. Data collection was very extensive and through an accurate statistical analysis we were able to show very detailed findings. Patient selection and post-surgical medications were performed in order to reduce as much as possible the presence of biases.

Table 6 Patient-reported willingness level. Table 6 Willingness: patiens willingness levels are reported as probability distributions and mean differences in the different groups. The data shown are indicative of the entire population and stratified by groups based on sex (SEX), smokers (SMK), hypertension (HYP), residual bone heigh (RBH), and periodontal
Future studies should have a larger sample size, a randomized controlled study design and analyze more variables, possibly more objectively, and for a longer observation period. Modified or customized OHIP- or OHRQOL questionnaire are auspicable.

Finally, since pain experienced by the patient can be connected or depend on his anxiety, future studies should contemplate anxiety control protocols that could lead to an improvement in the patient's experience.

disease (PER).Significant intergroup differences are marked in red and refer to the type of statistical test used. For each call, mean, standard deviation (SD), interquartile range (IQR), median, and the range of values were reported, indicating the minimum and maximum (min; max)

\begin{tabular}{|c|c|c|c|c|c|c|}
\hline & & \multicolumn{4}{|c|}{$\mathrm{N}^{\circ}$ of subjects (relative percentage) } & $\begin{array}{l}\text { Intergroup different (Mann-Whitney) } \\
\text { Mean } \pm \mathrm{SD} \text {; (IQR)-median (min; max) }\end{array}$ \\
\hline SUB & Total & $59(77.63)$ & $12(15.79)$ & $1(1.32)$ & $4(5.96)$ & $0.34 \pm 0.75 ;(0)-0(0 ; 3)$ \\
\hline \multirow[t]{3}{*}{ SEX } & M & $33(86.84)$ & $3(7.89)$ & $0(0)$ & $2(5.26)$ & $0.24 \pm 0.71 ;(0)-0(0 ; 3)$ \\
\hline & $\mathrm{F}$ & $26(68.42)$ & $9(23.68)$ & $1(2.63)$ & $2(5.26)$ & $0.45 \pm 0.80 ;(1)-0(0 ; 3)$ \\
\hline & Fisher's exact test & 0.1960 & & & & 0.0684 \\
\hline \multirow[t]{3}{*}{ SMK } & Y & $14(77.78)$ & $2(11.11)$ & $0(0)$ & $2(11.11)$ & $0.44 \pm 0.98 ;(0)-0(0 ; 3)$ \\
\hline & $\mathrm{N}$ & $45(77.69)$ & $10(17.24)$ & $1(1.72)$ & $2(3.45)$ & $0.31 \pm 0.68 ;(0)-0(0 ; 3)$ \\
\hline & Fisher's exact test & 0.5360 & & & & 0.9063 \\
\hline \multirow[t]{3}{*}{ HYP } & Y & $11(91.67)$ & $0(0)$ & $0(0)$ & $1(8.33)$ & $0.25 \pm 0.87 ;(0)-0(0 ; 3)$ \\
\hline & $\mathrm{N}$ & $48(75.00)$ & $12(18.75)$ & $1(1.56)$ & $3(4.69)$ & $0.36 \pm 0.74 ;(0.5)-0(0 ; 3)$ \\
\hline & Fisher's exact test & 0.4020 & & & & 0.2597 \\
\hline \multirow[t]{3}{*}{ RBH } & $<3$ & $27(75.00)$ & 7 (19.44) & $0(0)$ & $2(5.56)$ & $0.36 \pm 0.76 ;(0.5)-0(0 ; 3)$ \\
\hline & $>3$ & $32(80.00)$ & $5(12.50)$ & $1(2.50)$ & $2(5.00)$ & $0.33 \pm 0.76 ;(0)-0(0 ; 4)$ \\
\hline & Fisher's exact test & 0.4650 & & & & 0.6520 \\
\hline \multirow[t]{3}{*}{ PER } & Y & $23(76.67)$ & $5(16.67)$ & $0(0)$ & $2(6.67)$ & $0.37 \pm 0.81 ;(0)-0(0 ; 3)$ \\
\hline & $\mathrm{N}$ & $36(78.26)$ & $7(15.22)$ & $1(2.17)$ & $2(4.35)$ & $0.33 \pm 0.73 ;(0)-0(0 ; 0)$ \\
\hline & Fisher's exact test & 1.0000 & & & & 0.8665 \\
\hline \multirow[t]{3}{*}{ BCL } & A & $33(82.5)$ & $4(10)$ & $0(0)$ & $3(7.5)$ & $0.32 \pm 0.83 ;(0)-0(0 ; 3)$ \\
\hline & $\mathrm{C}$ & $26(72.22)$ & $8(22.22)$ & $1(2.78)$ & $1(2.78)$ & $0.36 \pm 0.68 ;(1)-0(0 ; 3)$ \\
\hline & Fisher's exact test & 0.2520 & & & & 0.3558 \\
\hline
\end{tabular}




\section{SWELLING AND ECCHYMOSIS}
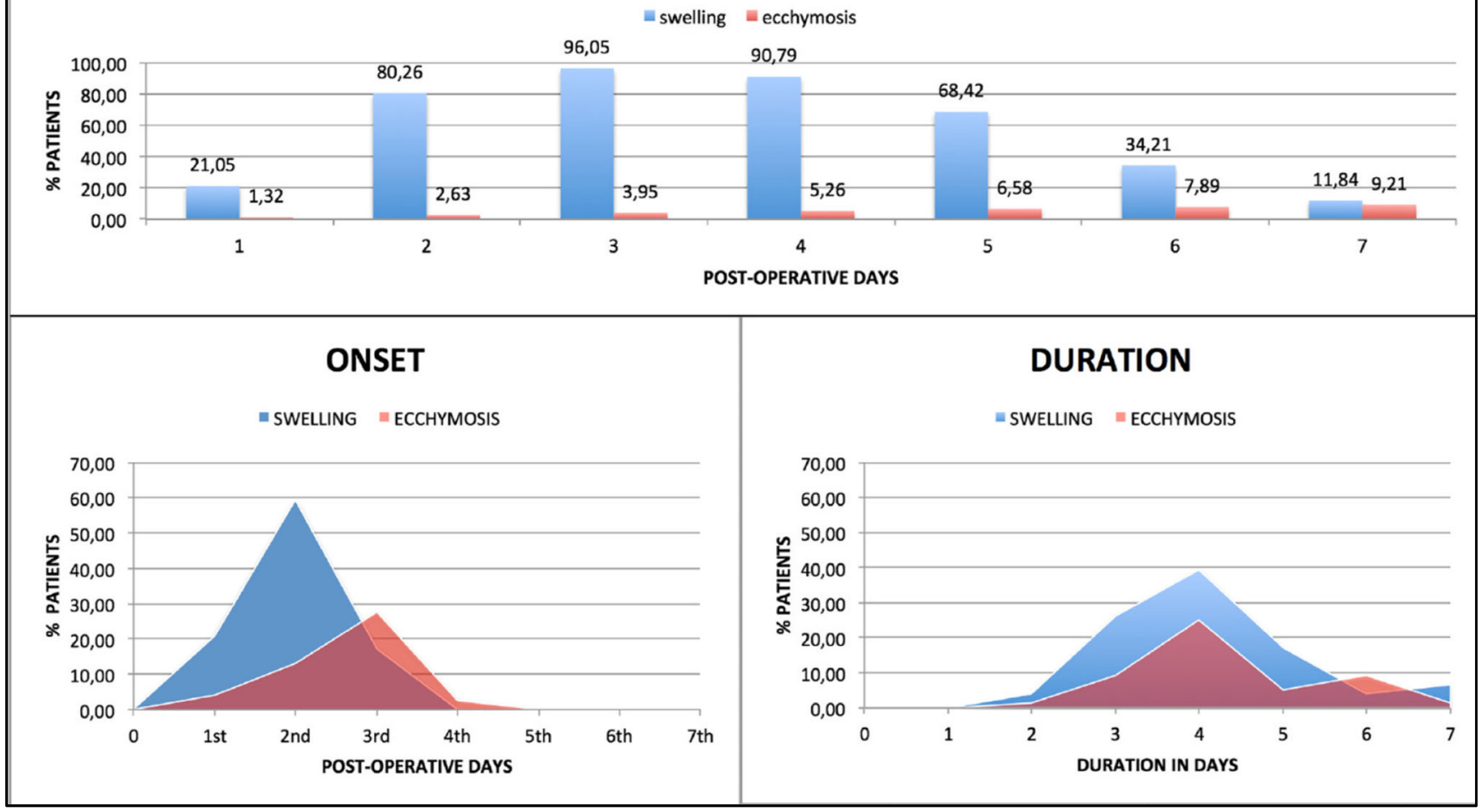

Fig. 4 Relative percentages of patients who experienced swelling and ecchymosis in the first post-operative days. Onset and duration of swelling and ecchymosis

This study confirmed that LSFE is a safe and predictable procedure because of moderate patient morbidity and very low complication rates. High level of willingness to undergo the same surgery should encourage clinicians to choose LSFE for bone augmentation in posterior maxilla.

\section{Acknowledgements GBR ACADEMY, Italy.}

Authors' contributions Carlo Rengo: conception; acquisition of data; drafting of the article. Antonino Fiorino: data analysis; revising of the article. Alessandro Cucchi: interpretation of data; revising of the article. Antonio Nappo: interpretation of data. Emanuele Randellini: interpretation of data. Paolo Calamai: revising of the article. Marco Ferrari: interpretation of data; final approval.

Funding Open access funding provided by Università degli Studi di Siena.

\section{Declarations}

Conflict of interest The authors declare that they have no conflict of interest.

Ethical approval All procedures performed were in accordance with the ethical standards of the institutional and/or national research committee and with the 1964 Helsinki declaration and its later amendments or comparable ethical standards.
Informed consent Informed consent was obtained from all individual participants included in the study.

Open Access This article is licensed under a Creative Commons Attribution 4.0 International License, which permits use, sharing, adaptation, distribution and reproduction in any medium or format, as long as you give appropriate credit to the original author(s) and the source, provide a link to the Creative Commons licence, and indicate if changes were made. The images or other third party material in this article are included in the article's Creative Commons licence, unless indicated otherwise in a credit line to the material. If material is not included in the article's Creative Commons licence and your intended use is not permitted by statutory regulation or exceeds the permitted use, you will need to obtain permission directly from the copyright holder. To view a copy of this licence, visit http://creativecommons.org/licenses/by/4.0/.

\section{References}

1. Muller E, Del Pilar Ríos Calvo M (2001) Pain and dental implantology: sensory quantification and affective aspects. Part I: At the Private Dental Office. Implant Dent 10:14-22. https://doi. org/10.1097/00008505-200101000-00007

2. Kim S, Lee Y-J, Lee S et al (2013) Assessment of pain and anxiety following surgical placement of dental implants. Int J Oral Maxillofac Implants 28:531-535. https://doi.org/10.11607/jomi. 2713

3. Al-Khabbaz AK, Griffin TJ, Al-Shammari KF (2007) Assessment of Pain associated with the surgical placement of dental implants. J Periodontol 78:239-246. https://doi.org/10.1902/jop.2007.060032 
4. Tan WC, Krishnaswamy G, Ong MMA, Lang NP (2014) Patientreported outcome measures after routine periodontal and implant surgical procedures. J Clin Periodontol 41:618-624. https://doi.org/ $10.1111 /$ jcpe. 12248

5. Farina R, Pramstraller M, Franceschetti G et al (2011) Alveolar ridge dimensions in maxillary posterior sextants: a retrospective comparative study of dentate and edentulous sites using computerized tomography data. Clin Oral Implants Res 22:1138-1144. https://doi.org/10.1111/j.1600-0501.2010.02087.x

6. Chiapasco M, Zaniboni M, Boisco M (2006) Augmentation procedures for the rehabilitation of deficient edentulous ridges with oral implants. Clin Oral Implants Res 17:136-159

7. Franceschetti G, Rizzi A, Minenna L et al (2017) Patient-reported outcomes of implant placement performed concomitantly with transcrestal sinus floor elevation or entirely in native bone. Clin Oral Implants Res 28:156-162. https://doi.org/10.1111/clr.12774

8. Alayan J, Ivanovski S (2018) A prospective controlled trial comparing xenograft/autogenous bone and collagen-stabilized xenograft for maxillary sinus augmentation - complications, patientreported outcomes and volumetric analysis. Clin Oral Implants Res 29:248-262. https://doi.org/10.1111/clr.13107

9. Moreno Vazquez JC, Gonzalez De Rivera AS, Gil HS, Mifsut RS (2014) Complication rate in 200 consecutive sinus lift procedures: guidelines for prevention and treatment. J Oral Maxillofac Surg 72: 892-901. https://doi.org/10.1016/j.joms.2013.11.023

10. Al-Nawas B, Schiegnitz E (2014) Augmentation procedures using bone substitute materials or autogenous bone - a systematic review and meta-analysis. Eur J Oral Implantol 7:S219-S234

11. Boyne P, James R (1980) Grafting of the maxillary sinus floor with autogenous marrow and bone. J Oral Surg (Chic) 38:613-616

12. Atalay B, Ramazanoglu M, Tozan EN, Ozyuvaci H (2017) Pain intensity and its objective determinants following implant surgery and sinus lifting: a 1-year prospective study. Niger J Clin Pract 20: 1139-1144. https://doi.org/10.4103/1119-3077.217253

13. Tatum OH (1986) Maxillary and sinus implant reconstruction. Dent Clin N Am 30:207-229

14. Lundgren S, Andersson S, Gualini F, Sennerby L (2004) Bone reformation with sinus membrane elevation: a new surgical technique for maxillary sinus floor augmentation. Clin Implant Dent Relat Res 6:165-173. https://doi.org/10.1111/j.1708-8208.2004. tb00224.x

15. Thoma DS, Zeltner M, Hüsler J et al (2015) EAO Supplement Working Group 4 - EAO CC 2015 Short implants versus sinus lifting with longer implants to restore the posterior maxilla: a systematic review. Clin Oral Implants Res 26:154-169. https://doi.org/ $10.1111 /$ clr. 12615

16. Apaza Alccayhuaman KA, Soto-Peñaloza D, Nakajima Y, et al (2018) Biological and technical complications of tilted implants in comparison with straight implants supporting fixed dental prostheses. A systematic review and meta-analysis. Clin Oral Implants Res 29:295-308. https://doi.org/10.1111/clr.13279

17. Araujo RZ, Santiago Júnior JF, Cardoso CL et al (2019) Clinical outcomes of pterygoid implants: systematic review and meta-analysis. J Cranio-Maxillofacial Surg 47:651-660. https://doi.org/10. 1016/j.jcms.2019.01.030

18. Aparicio C, Manresa C, Francisco K et al (2014) Zygomatic implants: indications, techniques and outcomes, and the Zygomatic Success Code. Periodontol 66:41-58. https://doi.org/10.1111/prd. 12038

19. Pommer B, Mailath-Pokorny G, Haas R et al (2014) Patients' preferences towards minimally invasive treatment alternatives for implant rehabilitation of edentulous jaws. Eur J Oral Implantol 7:S91S109

20. Malchiodi L, Giacomazzi E, Cucchi A, et al (2016) Journal of Oral Implantology Relationship between crestal bone levels and crownto-implant ratio of ultra-short
21. Atieh M, Zadeh B (2012) Survival of short dental implants for treatment of posterior partial edentulism: a systematic review. Int J Oral Maxillofac Implants 27:1323-1332

22. Chiapasco M, Zaniboni M (2009) Methods to treat the edentulous posterior maxilla: implants with sinus grafting. J Oral Maxillofac Surg 67:867-871. https://doi.org/10.1016/j.joms.2008.11.023

23. Monje A, Chan H-L, Fu J-H et al (2013) Are short dental implants $(<10 \mathrm{~mm})$ effective? A meta-analysis on prospective clinical trials. J Periodontol 84:895-904. https://doi.org/10.1902/jop.2012.120328

24. Nappo A, Rengo C, Pantaleo G et al (2019) Influence of implant dimensions and position on implant stability: a prospective clinical study in maxilla using resonance frequency analysis. Appl Sci 9:916. https://doi.org/10.3390/app9050860

25. Al-Almaie S, Kavarodi AM, Alorf A, Alzahrani S (2017) A splitmouth design comparison for lateral and crestal sinus lift techniques with dental implants placements: short communication. Open Dent J 11:603-608. https://doi.org/10.2174/1874210601711010603

26. Esposito M, Grusovin M, Rees J (2010) Effectiveness of sinus lift procedures for dental implant rehabilitation: a Cochrane systematic. Eur J Oral 3:7-26

27. Jordi C, Mukaddam K, Lambrecht JT, Kühl S (2018) Membrane perforation rate in lateral maxillary sinus floor augmentation using conventional rotating instruments and piezoelectric device-a meta-analysis. Int J Implant Dent 4. https://doi.org/10.1186/s40729017-0114-2

28. Merli M, Moscatelli M, Mariotti G et al (2016) A minimally invasive technique for lateral maxillary sinus floor elevation: a Bayesian network study. Clin Oral Implants Res 27:273-281. https://doi.org/ 10.1111/clr.12524

29. Scarano A, Lorusso F, Arcangelo M et al (2018) Lateral sinus floor elevation performed with trapezoidal and modified triangular flap designs: a randomized pilot study of post-operative pain using thermal infrared imaging. Int J Environ Res Public Health 15. https:// doi.org/10.3390/ijerph15061277

30. Younes F, Eghbali A, Goemaere T et al (2018) Patient-reported outcomes after lateral wall sinus floor elevation. Implant Dent 1. https://doi.org/10.1097/id.0000000000000717

31. Elm E, Altman D, Egger M et al (2007) Strengthening the Reporting of Observational Studies in Epidemiology ( STROBE ) Statement : guidelines for reporting observational studies. Ann Intern Med 147:573-578

32. Chiapasco M, Zaniboni M, Rimondini L (2008) Dental implants placed in grafted maxillary sinuses: a retrospective analysis of clinical outcome according to the initial clinical situation and a proposal of defect classification. Clin Oral Implants Res 19:416-428. https:// doi.org/10.1111/j.1600-0501.2007.01489.x

33. Deppe H, Mücke T, Wagenpfeil S, Hölzle F (2012) Sinus augmentation with intra- vs extraorally harvested bone grafts for the provision of dental implants: clinical long-term results. Quintessence Int 43:469-481

34. Farina R, Franceschetti G, Travaglini D et al (2018) Morbidity following transcrestal and lateral sinus floor elevation: a randomized trial. J Clin Periodontol 45:1128-1139. https://doi.org/10. $1111 /$ jcpe. 12985

35. Younes F, Cosyn J, De Bruyckere T et al (2019) A 2-year prospective case series on volumetric changes, PROMs, and clinical outcomes following sinus floor elevation using deproteinized bovine bone mineral as filling material. Clin Implant Dent Relat Res 21: 301-309. https://doi.org/10.1111/cid.12730

36. Nickenig HJ, Wichmann M, Zöller JE, Eitner S (2014) 3-D based minimally invasive one-stage lateral sinus elevation - a prospective randomized clinical pilot study with blinded assessment of postoperative visible facial soft tissue volume changes. J CranioMaxillofacial Surg 42:890-895. https://doi.org/10.1016/j.jcms. 2014.01.006 
37. Merli M, Moscatelli M, Mariotti G et al (2013) Autogenous bone versus deproteinised bovine bone matrix in 1-stage lateral sinus floor elevation in the severely atrophied maxilla: a randomised controlled trial. Eur J Oral Implantol 6:27-37

38. Del Fabbro M, Corbella S, Ceresoli V et al (2015) Plasma rich in growth factors improves patients' postoperative quality of life in maxillary sinus floor augmentation: preliminary results of a randomized clinical study. Clin Implant Dent Relat Res 17:708-716. https://doi.org/10.1111/cid.12171

39. Ozturan S, Sirali A, Sur H (2015) Effects of Nd : YAG laser irradiation for minimizing edema and pain after sinus lift surgery randomized controlled clinical trial. Photomed Laser Surg 33:193199. https://doi.org/10.1089/pho.2014.3823

40. Delilbasi C, Gurler G (2013) Comparison of piezosurgery and conventional rotative instruments in direct sinus lifting. Implant Dent 22:662-665. https://doi.org/10.1097/ID.0000000000000001

41. Mardinger O, Poliakov H, Beitlitum I et al (2009) The patient's perception of recovery after maxillary sinus augmentation: a prospective study. J Periodontol 80:572-576. https://doi.org/10.1902/ jop.2009.080536

42. Pieri F, Aldini NN, Fini M et al (2012) Immediate fixed implant rehabilitation of the atrophic edentulous maxilla after bilateral sinus floor augmentation: a 12-month pilot study. Clin Implant Dent Relat Res 14:67-82. https://doi.org/10.1111/j.1708-8208.2011. 00360.x

43. Staderini E, Patini R, Guglielmi F, Camodeca A (2019) How to manage impacted third molars : germectomy or delayed removal ? a systematic literature review. 1-14. https://doi.org/10.3390/ medicina55030079

44. Deppe H, Horch HH, Schrödl V et al (2007) Effect of 308-nm excimer laser light on peri-implantitis-associated bacteria - an in vitro investigation. Lasers Med Sci 22:223-227. https://doi.org/ 10.1007/s10103-007-0441-2

45. Weisensee W, Scheer M, Müller L et al (2012) Impact of anxiety parameters on prospective and experienced pain intensity in implant surgery. Implant Dent 21:502-506. https://doi.org/10.1097/ID. 0b013e3182703a44
46. Giannoudis PV, Hak D, Sanders D et al (2015) Inflammation, bone healing, and anti-inflammatory drugs: an update. J Orthop Trauma 29:S6-S9. https://doi.org/10.1097/BOT.0000000000000465

47. Mountziaris PM, Spicer PP, Kasper FK, Mikos AG (2011) Harnessing and modulating inflammation in strategies for bone regeneration. Tissue Eng - Part B Rev 17:393-402. https://doi. org $/ 10.1089 /$ ten.teb.2011.0182

48. Schwartz-Arad D, Herzberg R, Dolev E (2004) The Prevalence of surgical complications of the sinus graft procedure and their impact on implant survival. J Periodontol 75:511-516. https://doi.org/10. 1902/jop.2004.75.4.511

49. Viña-Almunia J, Peñarrocha-Diago $M$, Peñarrocha-Diago $M$ (2009) Influence of perforation of the sinus membrane on the survival rate of implants placed after direct sinus lift. Literature update. Med Oral Patol Oral Cir Bucal 14:133-136

50. Geminiani A, Weitz DS, Ercoli C et al (2015) A comparative study of the incidence of schneiderian membrane perforations during maxillary sinus augmentation with a sonic oscillating handpiece versus a conventional turbine handpiece. Clin Implant Dent Relat Res 17:327-334. https://doi.org/10.1111/cid.12110

51. Atieh M, Alsabeeha N, Tawse-Smith A et al (2015) Piezoelectric surgery vs rotary instruments for lateral maxillary sinus floor elevation: a systematic review and meta-analysis of intra- and postoperative complications. Int J Oral Maxillofac Implants 30:12621271. https://doi.org/10.11607/jomi.3895

52. Tan WL, TLT W, MCM W, Lang NP (2012) A systematic review of post-extractional alveolar hard and soft tissue dimensional changes in humans. Clin Oral Implants Res 23:1-21. https://doi. org/10.1111/j.1600-0501.2011.02375.x

53. Hernández-Alfaro F, Torradeflot MM, Marti C (2008) Prevalence and management of Schneiderian membrane perforations during sinus-lift procedures. Clin Oral Implants Res 19:91-98. https:// doi.org/10.1111/j.1600-0501.2007.01372.x

Publisher's note Springer Nature remains neutral with regard to jurisdictional claims in published maps and institutional affiliations. 